\title{
REGENERAÇÃO DE UM SOLO SOB AGRICULTURA ORGÂNICA EM DIFERENTES MANEJOS: ESTAÇÃO EXPERIMENTAL DA PESAGRO, PATY DO ALFERES - RIO DE JANEIRO
}

\section{Regeneration of a soil over defferent managements of organic agriculture: Experimental Sation of PESAGRO, Paty do Alferes - Rio de Janeiro.}

Rafaella Lima Paixão Fontes Mestranda em Geografia pela Universidade Federal do Rio de Janeiro, Pós-graduada em Dinâmicas Urbano-Ambientais e Gestão do Território pela UERJ/FFP rafalpf@yahoo.com.br

Gisele Rodrigues Gomes Pós-Graduada em Dinâmicas Urbano-Ambientais UERJ/FFP gisele_rg@yahoo.com.br

Ana Valéria Freire Allemão Bertolino Professor adjunto do Departamento de Geografia UERJ/FFP anabertolino@uol.com.br

Luiz Carlos Bertolino Professor adjunto do Departamento de Geografia UERJ/FFP lcbertolino@uol.com.br

Artigo recebido em 15/02/2013 e aceito para publicação em 15/04/2013

DOI: 10.12957/tamoios.2013.4980

RESUMO Os problemas gerados pelo uso inadequado do solo agrícola têm despertado cada vez mais o interesse de estudiosos e pesquisadores. A partir dessas preocupações, o estudo objetivou observar as alterações das propriedades físicas e químicas do solo (granulometria e densidade aparente) bem como avaliar as modificações ocorridas na sua morfologia e como a forma de manejo influencia nos processos hidroerosivos associando este à pluviosidade durante o período do verão 2009/2010. O trabalho foi realizado na Estação Experimental da PESAGRO, Paty do Alferes - RJ, composta por três áreas experimentais: 1) Sem Cobertura (SC), 2) Plantio convencional (PC) e 3) Cultivo Mínimo (CM). O sistema $\mathrm{Cm}$ apresentou menor DAP (Densidade Aparente) em superfície $\left(1,09 \mathrm{~g} / \mathrm{cm}^{3}\right)$, conectividade poral e quantificação poral mais homogênea $(32,8 \% ; 33,1 \% ; 33,3 \%)$ e maior teor de C-Total (Carbono Orgânico Total) $(5,1 \%)$ em detrimento aos outros dois usos, demonstrando a importância da manutenção da estrutura do solo, através de um manejo conservacionista.

Palavras-chave: Erosão hídrica; manejo do solo.

ABSTRACT The problems caused by inappropriate use of agricultural land has increasingly attracted the interest of scholars and researchers. Based on these concerns, the study aimed to observe the changes of physical and chemical properties of soil (particle size and density) as well as to assess the changes occurring in their morphology and as a way to influence management water erosion processes linking this to rainfall during the period Summer 2009/2010. The study was conducted at the Experimental Station of PESAGRO, Paty do Alferes - RJ, composed of three experimental areas: 1) No Cover (SC), 2) Planting conventional (PC) and 3) Minimum Tillage (CM). The system CM showed lower DAP on the surface $\left(1.09 \mathrm{~g} / \mathrm{cm}^{3}\right)$, poral connectivity and more homogeneous poral quantification $(32,8 \% ; 33,1 \% ; 33,3 \%)$ and higher levels of total-C (5, $1 \%)$ over the other two uses, demonstrating the importance of maintaining the soil structure, via a conservation tillage.

Keywords: Water erosion; soil management 


\section{INTRODUÇÃO}

A erosão é a mais extensiva e preocupante das oito categorias de degradação antrópica do solo estabelecidas (Hudson, 1995), já que as taxas de desgaste e remoção de solo pela erosão podem superar infinitamente as taxas (naturais e artificiais) de renovação e reposição superficial de solo.

O uso intensivo do solo por práticas agrícolas, dissociadas da adoção de técnicas conservacionistas, resultam em intensa degradação, principalmente nos países tropicais, caracterizados por uma alta taxa pluviométrica que acaba por aumentar a frequência e magnitude dos processos hidroerosivos.

Bertoni e Lombardi Neto (1999) atestam que tal problema afeta a vida de várias formas, manifestando-se nas regiões agrícolas como: perda de solos agricultáveis, diminuindo as áreas de plantio; redução da fertilidade das partes superficiais do solo, a partir da perda de nutrientes por escoamento superficial; e menor produtividade agrícola.

Práticas selecionadas de manejo aumentam o teor de matéria orgânica no solo e melhoram sua estrutura como um todo, incluindo as propriedades físicas, químicas e biológicas, refletindo em maior rendimento das culturas (Portela et al., 2010).

Assim, práticas que buscam o aporte contínuo e abundante de matéria orgânica ao solo, associadas a métodos conservacionistas de preparo, são de fundamental importância na recuperação de solos fisicamente degradados (Portela et al, 2010).

\section{ÁREA DE ESTUDO}

A área de estudo, o município de Paty do Alferes - RJ (Figura 1A e 1B) localiza-se na região Centro-sul do Estado do Rio de Janeiro, coordenadas de $22^{\circ} 21^{\prime} \mathrm{S}$ de latitude e $43^{\circ} 25^{`} \mathrm{~W}$ de longitude. Caracteriza-se por uma região produtora de olericultura de extrema importância para o Estado do Rio de Janeiro. Composta por pequenos e médios agricultores que, em geral, utilizam técnicas convencionais (técnica do trator morro abaixo) desconsiderando os aspectos naturais da região.
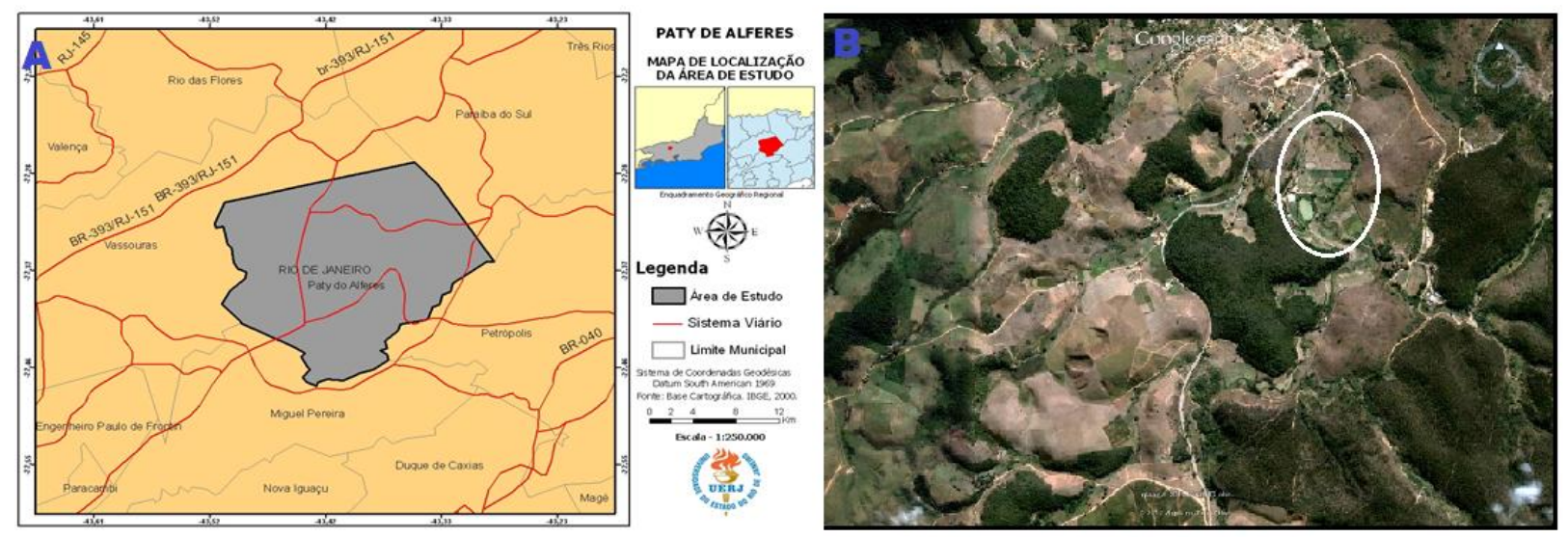

Figura 1: A) Mapa de localização do município de Paty do Alferes; B) Demonstração do relevo da região, a partir do Google Earth, onde a área em destaque refere-se à Estação Experimental da PESAGRO.

Desde 1995 estudos voltados para a caracterização do meio físico, biótico, econômico e social foram desenvolvidos no município de Paty do Alferes através do Projeto DESUSMO (Embrapa, 1998), mais especificamente, no córrego do Saco-rio Ubá (Lumbreras et al., 1998; Kunzmann et al., 1998; Marques e Pinheiro, 1998; entre outros) tendo como meta buscar soluções para os problemas ambientais da região.

A partir dos trabalhos citados acima, constatou-se que a sua morfologia é caracterizada por 
Regeneração de um solo sob agricultura orgânica em diferentes manejos: Estação Experimental da PESAGRO, Paty do Alferes - Rio de Janeiro. Rafaella Lima Paixão Fontes, Gisele Rodrigues Gomes, Ana Valéria Freire Allemão Bertolino e Luiz Carlos Bertolino contrastes entre as serras e colinas onduladas que foram desenvolvidas sobre rochas metamórficas do pré-cambriano e o relevo da região apresenta declividade média de $25 \%$.

Segundo Calderano \& Lemos (1998), ocorrem na região duas formações geológicas, principais, denominadas de Unidade Santo Eduardo e Unidade Rio Negro (DRM, 1995). Estas Unidades são constituídas, em geral, por gnaisses, com predomínio de biotita-gnaisse, tipo granatífero, de textura variada e são datadas no pré-cambriano e são cortadas localmente, nas zonas principais de fraturamento, por diques de rocha básica, relacionada ao magmatismo básico, do período Cretácio. Nos topos aplainados que ocorrem em toda área, registra-se a presença de sedimento argilo-arenosos, que poderão ser correlacionáveis em idade ao Terciário/Quaternário, além, da presença de sedimentos argilo-arenosos de natureza aluvionar e colúvio-aluvionar, de idades mais recentes nas áreas ao longo das drenagens principais, preenchendo fundos de vales, sopé de encostas, formando terraços típicos de baixa declividade. Em muitos locais, independente da altitude e, às vezes, até mesmo da forma das encostas e declividade, encontra-se uma cobertura de natureza estritamente coluvionar. Ocorrem ainda pequenas porções de rochas granulíticas, provavelmente pertencentes às Unidades Monte Verde e São José de Ubá. Todas estas Unidades são de idade pré-cambriana e são cortadas localmente, nas zonas principais de fraturamento, por diques de rocha básica, relacionada ao magmatismo básico, do período Cretáceo. Nos topos aplainados, presentes em toda a área, foram registrados a presença de sedimentos argilo-arenosos, que podem ser correlacionáveis em idade ao Terciário/ Quaternário.

Segundo Silva et al. (1998), a região apresenta três principais domínios geomorfológicos: o primeiro relacionado às feições de degraus e serras escarpados e reafeiçoados (representados pelas classes de desnivelamento > 400m (D1) e 200 a 400m (DR3), respectivamente) nivelados a altitudes que variam de 950 a $1800 \mathrm{~m}$, localizados a SE do município; o segundo, referente aos compartimentos de colinas suaves, com predomínio de classes de desnivelamento de 50 a $100 \mathrm{~m}$ e altitudes que variam de 450 a $650 \mathrm{~m}$, correspondendo à porção central do município, ao longo do vale do córrego do Saco/rio Ubá (C1); e um terceiro associado à presença de compartimentos de degraus reafeiçoados e colinas dissecadas (DR1), com altitudes em torno de 550 a $850 \mathrm{~m}$, a NW do município.

Segundo Embrapa (1998) há o predomínio de LATOSSOLO VERMELHO-AMARELO (LV) Distrófico típico na área das parcelas.

De acordo com Marques \& Pinheiro (1998), o regime pluviométrico caracteriza-se por um período chuvoso de sete a oito meses, que coincide com o verão. O período seco coincide com o inverno e apresenta cinco meses com precipitação menor que $60 \mathrm{~mm}$. O índice pluviométrico apresenta um total anual de aproximadamente $1200 \mathrm{~mm}$.

O trabalho foi, mais especificamente, desenvolvido na Estação Experimental da PESAGRO, em Avelar, Paty do Alferes-RJ. Esta região apresenta três parcelas de erosão do tipo Wishmeier \& Smith (1958) com $88 \mathrm{~m}^{2}$ (Figura 2), conectadas a duas caixas coletoras de sedimentos, cada parcela, com capacidade para 500 e 1000 litros, visando o armazenamento de material erodido por escoamento superficial. Entre as parcelas encontra-se um pluviógrafo, que mensura a precipitação diária. 


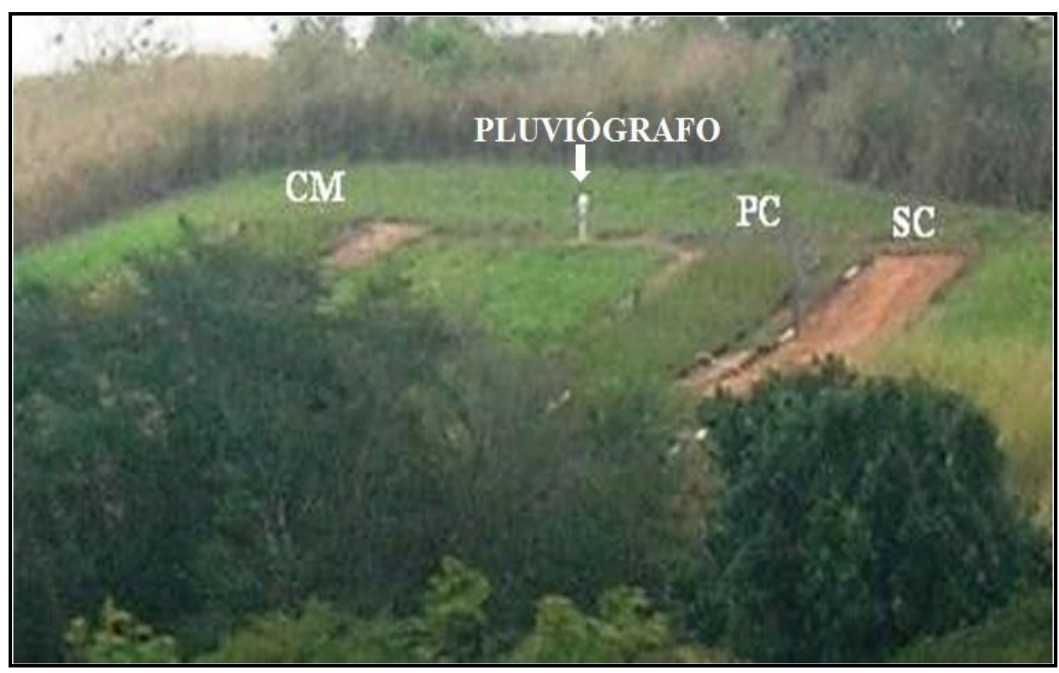

Figura 2: Visão detalhada das Parcelas de Erosão de Cultivo Mínimo (CM), Plantio Convencional (PC) e Sem

Cobertura Vegetal (SC) na Estação Experimental da PESAGRO em Avelar, Paty do Alferes - RJ.

As parcelas apresentam os seguintes usos: Sem Cobertura Vegetal (SC) - sem a presença de cobertura vegetal; Plantio Convencional (PC) - plantio que utiliza a mecanização a partir da técnica do trator morro a baixo, resultando no revolvimento da camada superficial do solo; Cultivo Mínimo (CM) - plantio que visa a uma pouca movimentação do solo, onde são feitas apenas covas para o depósito das sementes e preservação da cobertura vegetal morta na superfície do solo.

Segundo Kunzmann et al. (1998), a área onde estão inseridas as parcelas possui uma declividade de $30 \%$.

\section{MATERIAIS E MÉTODOS}

Para as análises de micromorfologia foram coletados blocos indeformados utilizando-se caixas do tipo Kubiena de dimensões 11 x 5,5 cm e 3,5 cm de profundidade, nos intervalos de 0-11, 11-22 e 25-36 cm do perfil de solo. As amostras foram coletadas na posição vertical em mini-trincheiras, na parte inferior das parcelas de erosão, bem como em área de floresta onde se mantêm inalterada há mais ou menos 60 anos.

Após a coleta, os blocos de solo foram secos ao ar e impregnados a vácuo na unidade LOGITEC® IU-20. Para impregnação utilizou-se uma mistura de resina do tipo epóxi, endurecedor e álcool etílico (solvente), na proporção de 5:2:1.

A partir dos blocos impregnados foram confeccionadas lâminas delgadas pequenas $(6 \times 2,5 \mathrm{~cm})$ no Laboratório de Laminação do Departamento de Geologia - UFRJ.

A descrição micromorfológica, bem como as fotomicrografias, realizadas com o auxílio de um microscópio petrográfico Axioplan Zeiss ${ }^{\circledR}$, das lâminas dos três diferentes manejos foi realizada no Centro de Tecnologia Mineral - CETEM. Foram utilizadas as terminologias sugeridas por Bullock et al. (1985); Brewer (1976); Brewer \& Sleeman (1960), compiladas por Castro (2002).

Para a quantificação poral foi realizado o método de contagem de pontos descrita por Eswaran 
Regeneração de um solo sob agricultura orgânica em diferentes manejos: Estação Experimental da PESAGRO, Paty do Alferes - Rio de Janeiro. (1968) e Brewer (1976). Rafaella Lima Paixão Fontes, Gisele Rodrigues Gomes, Ana Valéria Freire Allemão Bertolino e Luiz Carlos Bertolino

As análises de Carbono orgânico total foram realizadas nas profundidades de 0-5 cm e $5-10 \mathrm{~cm}$ das porções superior, média e inferior da encosta, que apresenta declividade de 30\%, totalizando 12 amostras. Foram consideradas nesta avaliação somente as parcelas com Plantio Convencional e Cultivo Mínimo.

As amostras foram trabalhadas, obtendo-se o C-Total a partir do método da Queima do Carbono Orgânico em Meio Ácido (Embrapa, 1998).

As medições de perda de solo e água foram obtidas de acordo com a ocorrência de eventos chuvosos e do escoamento superficial decorrente. O material erodido fica depositado na(s) caixa(s) coletora(s) de cada parcela, que possui duas caixas, onde a primeira caixa tem capacidade de retenção de 500 litros e, a segunda, caixa com capacidade de 1000 litros. Entre as duas caixas existe uma tela com 12 subdivisões para saída da água escoada.

O material erodido disposto na caixa é homogeneizado e a partir deste é retirado 1 litro, sendo o resto descartado após anotação da quantidade total e caso a caixa apresente uma coleta inferior a 1 litro retira-se todo o conteúdo. A quantificação total do material é feita a partir da medição da altura das perdas de sedimentos e água através de uma régua de $80 \mathrm{~cm}$ e então são realizados cálculos de proporção no Laboratório de Geociência da UERJ-FFP.

\section{RESULTADOS}

\section{Propriedades físicas do solo}

A análise da diferenciação da porosidade nos diferentes tratamentos torna-se uma variável preponderante, pois sabe-se que diferentes manejos podem causar transformações ao longo do perfil, principalmente em relação à porosidade e o grau de compactação. Desta forma, a sua caracterização torna-se um parâmetro importante na avaliação da dinâmica hidrológica e dos processos erosivos.

A densidade aparente (Tabela 1) demonstra que há aumento da compactação com a profundidade, indicando uma menor compactação do solo na porção superficial. A profundidade de 0$5 \mathrm{~cm}$ apresentou as menores variações dos valores em todos os tratamentos, sendo que o sistema CM apresentou o menor valor e o sistema SC o maior, 1,09 e $1,27 \mathrm{~g} / \mathrm{cm}^{3}$, respectivamente.

Os maiores valores no sistema SC estão relacionados à ausência de cobertura vegetal, que pode acarretar compactação e selamento da superfície do solo. Constata-se que a porção superficial da parcela SC apresenta $1,27 \mathrm{~g} / \mathrm{cm}^{3}$ e valores menores em subsuperfície 1,20 e $1,33 \mathrm{~g} / \mathrm{cm}^{3}$.

Na profundidade de 15-20 cm verificam-se valores mais elevados em relação à profundidade de 0-5 cm; nos sistemas PC e CM ocorreram as maiores variações de densidade aparente, 1,20 e 1,47 $\mathrm{g} / \mathrm{cm}^{3}$, respectivamente.

O sistema PC apresenta diferenças significativas somente entre as profundidades de 0-5 e 15-20 $\mathrm{cm}$. O sistema CM apresenta diferenças entre as profundidades de 0-5 e 15-20 cm cujo, respectivos, valores variam de 1,09 a 1,47 e entre $15-20 \mathrm{~cm}$ e $30-35 \mathrm{~cm}$ cujos valores variam de 1,47 a 1,53 (Tabela 1).

Valores similares foram encontrados por Macedo et al. (1997) em diferentes LATOSSOLOS de Paty do Alferes. Os autores afirmam que esses valores podem ser considerados elevados para essa classe de solo, pois normalmente os valores encontrados são da ordem de 1,05 a 1,20 g/ $\mathrm{cm}^{3}$. Segundo

Rev. Tamoios, São Gonçalo (RJ), ano 09, n. 1, pags. 28- 41, jan/jun. 2013 
Regeneração de um solo sob agricultura orgânica em diferentes manejos: Estação Experimental da PESAGRO, Paty do Alferes - Rio de Janeiro. Rafaella Lima Paixão Fontes, Gisele Rodrigues Gomes, Ana Valéria Freire Allemão Bertolino e Luiz Carlos Bertolino os mesmos, isto pode estar relacionado ao manejo e à posição topográfica, pois os LATOSSOLOS desta área estão posicionados em região de relevo movimentado e com altas precipitações, sendo, ainda, intensamente cultivados.

O valor mais baixo na camada superficial pode estar relacionado à atividade biológica, raízes e à presença de carbono orgânico que beneficiam a estabilidade dos agregados. Em contrapartida, em subsuperfície é natural a presença de camadas mais compactadas, devido à pressão exercida pelas camadas superiores.

$\mathrm{O}$ menor valor verificado no sistema $\mathrm{CM}(0-5 \mathrm{~cm})$ pode estar relacionado às características deste sistema já observadas por outros autores na área em questão (Turetta, 2000; Pinheiro, 2002).

Nas áreas de Cultivo Mínimo é natural o aumento da densidade aparente nos primeiros anos de manejo, pois o não revolvimento do solo pode resultar num maior adensamento da matriz. Entretanto, ao longo do tempo, com a incorporação de matéria orgânica, a compactação tende a diminuir (Fernandes et al., 1983).

Tabela 1: Valores de propriedades físicas do solo - Densidade Aparente, Porosidade Total, Macroporosidade e Microporosidade, nos sistemas Cultivo Mínimo (CM), Plantio Convencional (PC) e Sem Cobertura Vegetal (SC). Fonte: Bertolino (2004).

\section{\begin{tabular}{l|l|l} 
PROF $(\mathrm{cm})$ & DENSIDADE APARENTE $\left(\mathrm{g} / \mathrm{cm}^{3}\right)$ & MACROPOROSIDADE $(\%)$
\end{tabular}}

\begin{tabular}{|c|c|c|c|c|c|c|}
\hline & $\mathrm{CM}$ & PC & SC & $\mathrm{CM}$ & PC & SC \\
\hline $0-5$ & 1,09 & 1,23 & 1,27 & 39,2 & 37,5 & 36,1 \\
\hline $15-20$ & 1,47 & 1,38 & 1,20 & 21,7 & 28,9 & 37 \\
\hline $30-35$ & 1,53 & 1,41 & 1,33 & 22,8 & 26,3 & 27,1 \\
\hline & \multicolumn{3}{|c|}{ POROSIDADE TOTAL (\%) } & \multicolumn{3}{|c|}{ MICROPOROSIDADE (\%) } \\
\hline & $\mathrm{CM}$ & $\mathrm{PC}$ & $\mathrm{SC}$ & $\mathrm{CM}$ & $\mathrm{PC}$ & $\mathrm{SC}$ \\
\hline $0-5$ & 30,7 & 32,3 & 29 & 30,7 & 32,3 & 29 \\
\hline $15-20$ & 36,2 & 34,4 & 28,7 & 36,2 & 34,4 & 28,7 \\
\hline $30-35$ & 31,5 & 28,7 & 31 & 31,5 & 28,7 & 31 \\
\hline
\end{tabular}

Analisando os dados de porosidade (Tabela 1), observou-se que os valores de porosidade total são menores em superfície. A profundidade de 0-5 cm apresenta valores de 29,0 a $30,7 \%$ e a profundidade de $30-35 \mathrm{~cm}$, percentuais de 28,7 a 31,5\%. Estudos desenvolvidos na região por Macedo et al. (1997) mostram que os LATOSSOLOS apresentam porosidade total em torno de $47 \%$, sendo que os valores encontrados neste estudo estão um pouco abaixo da faixa obtida por esses autores.

Observa-se na camada superficial $(0-5 \mathrm{~cm})$ que os sistemas CM e PC apresentaram os maiores percentuais. Na profundidade de $15-20 \mathrm{~cm}$, ocorreram as maiores diferenciações entre os sistemas, com destaque para SC e CM, que apresentaram, respectivamente, o maior e menor valor $(36,2$ e 28,7\%). Na profundidade de 30-35 não foram encontradas grandes distinções dos valores da entre os sistemas. Desta maneira, os dados demonstram que com o aumento da profundidade poderá ocorrer redução no processo de infiltração nos diferentes sistemas.

Apesar do sistema CM apresentar a menor porosidade total em subsuperfície, Wu et al. (1992) ressaltam que os poros do mesmo transmitem água de forma mais eficaz do que os do sistema convencional, o que faz com que o solo do sistema CM, mesmo apresentando porosidade total menor, 
Regeneração de um solo sob agricultura orgânica em diferentes manejos: Estação Experimental da PESAGRO, Paty do Alferes - Rio de Janeiro. Rafaella Lima Paixão Fontes, Gisele Rodrigues Gomes. Ana Valéria Freire Allemão Bertolino e Luiz Carlos Bertolino tenha uma condutividade hidráulica maior ou igual à do PC. Turetta (2000) encontrou curvas com maiores valores de infiltração no sistema CM e menor no sistema SC. Nos primeiros cinco minutos, o sistema CM apresentou a maior velocidade de infiltração. O comportamento do CM pode estar relacionado à continuidade dos macroporos ou à diversidade da fauna edáfica. Os sistemas PC e CM apresentaram valores próximos na camada mais superficial. Em profundidade $(10-20 \mathrm{~cm})$, houve um aumento da condutividade para o sistema CM. O autor associa tal fato à melhor distribuição dos poros nesta profundidade.

Na macroporosidade, Tabela 1, há um decréscimo com o aumento da profundidade em todos os tratamentos (39,2 a 22,8\% em CM e 37,5 a 26,3\% em PC), com exceção do sistema SC. Na camada de 0-5 cm, o maior valor está relacionado ao sistema CM, com 39,2\%. Na profundidade de $15-20 \mathrm{~cm} \mathrm{o}$ sistema SC apresenta o maior valor, com 37,0\%, vindo em seguida o PC (28,9\%) e CM (21,7\%). Há variações significativas entre todos os tratamentos. Nota-se que os maiores valores estão relacionados aos sistemas que sofreram um preparo do solo mais intenso.

Os resultados demonstram que na profundidade de $0-5 \mathrm{~cm}$ há uma similaridade, sendo que o sistema CM apresenta o maior percentual. Já o sistema PC apresenta uma diminuição da macroporosidade com o aumento da profundidade.

A microporosidade, Tabela 1, na profundidade de $0-5 \mathrm{~cm}$ apresenta um comportamento mais homogêneo entre os diferentes sistemas. Na profundidade de $15-20 \mathrm{~cm}$ os valores dos sistemas CM e PC tenderam a aumentar. Já o sistema SC apresentou comportamento inverso, na camada de $15-20 \mathrm{~cm}$ não houve um aumento na variação da microporosidade. $\mathrm{Na}$ profundidade de $30-35 \mathrm{~cm}$ os sistemas CM e SC tiveram valores maiores, enquanto o PC teve um valor menor com relação a profundidade de $15-20 \mathrm{~cm}$.

Macedo et al (1997), estudando os solos da região, verificaram que a microporosidade variou de $27 \%$ a $40 \%$, estando os valores de acordo com os encontrados neste estudo.

\section{Micromorfologia do solo}

A descrição das lâminas delgadas dos três sistemas demonstra que o esqueleto apresenta um percentual elevado de grãos, variando de 30 a 40\%, em todos os perfis e profundidades. Foi observada, também, a orientação preferencial dos grãos em alguns pontos nas lâminas da Área de Floresta (T0) e do sistema CM, indicando atividade biológica.

O T0 (Figura 3) apresentou em todas as profundidades grande concentração de macroporos com boa conexão entre eles. Seu plasma possui uma coloração marrom-escura, em todas as profundidades, devido à complexação das argilas com matéria orgânica.

Possui presença de um alto índice de pelotas fecais, no caso, esféricas de coloração amareladas, avermelhadas e pretas, preenchendo parcialmente canais e cavidades e dentro de raízes, em todas as profundidades, caracterizando uma atividade biológica homogênea e atuante. Além da presença de raízes em estágios iniciais e avançados de decomposição. Observa-se, então, uma homogeneidade em sua estrutura, o que nos remete à proximidade do equilíbrio nesse sistema.

Rev. Tamoios, São Gonçalo (RJ), ano 09, n. 1, pags. 28- 41, jan/jun. 2013 
Regeneração de um solo sob agricultura orgânica em diferentes manejos: Estação Experimental da PESAGRO, Paty do Alferes - Rio de Janeiro. Rafaella Lima Paixão Fontes, Gisele Rodrigues Gomes, Ana Valéria Freire Allemão Bertolino e Luiz Carlos Bertolino
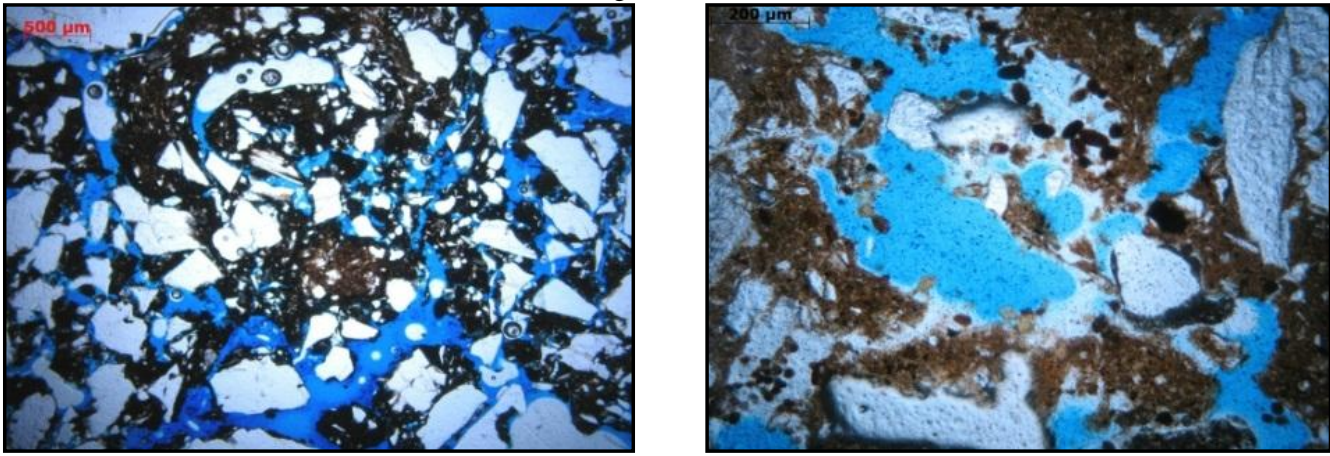

Figura 3: Fotomicrografias do solo do T0. LP: Luz plana. Aumento de 10x.

No sistema CM (Figura 4) na profundidade de 0-11 cm ocorre a presença de raízes em estágios iniciais e avançados de decomposição semelhantes ao T0, além da presença de pelotas fecais esféricas de coloração escura, preenchendo parcialmente canais e cavidades. Apresenta, também, principalmente poros planares de rachaduras e oblíquos, maioria de ortoporos e presença de alguns metaporos, caracterizados pela atividade biológica.

$\mathrm{Na}$ profundidade de 11-22 $\mathrm{cm}$, há presença de raízes e excrementos, porém menos significativas. Verificou-se também a presença de pedotúbulos, mesmo que preenchidos, que indica atividade biológica.

Na profundidade $25-36 \mathrm{~cm}$, vestígios de pelotas fecais e esféricas dentro das raízes, além das que preenchem canais e cavidades, demonstrando que neste sistema a atividade biológica atua em maiores profundidades.

A coloração do sistema CM é, em geral, marrom escura caracterizada pela presença de material orgânico, tendo grande semelhança com o T0.
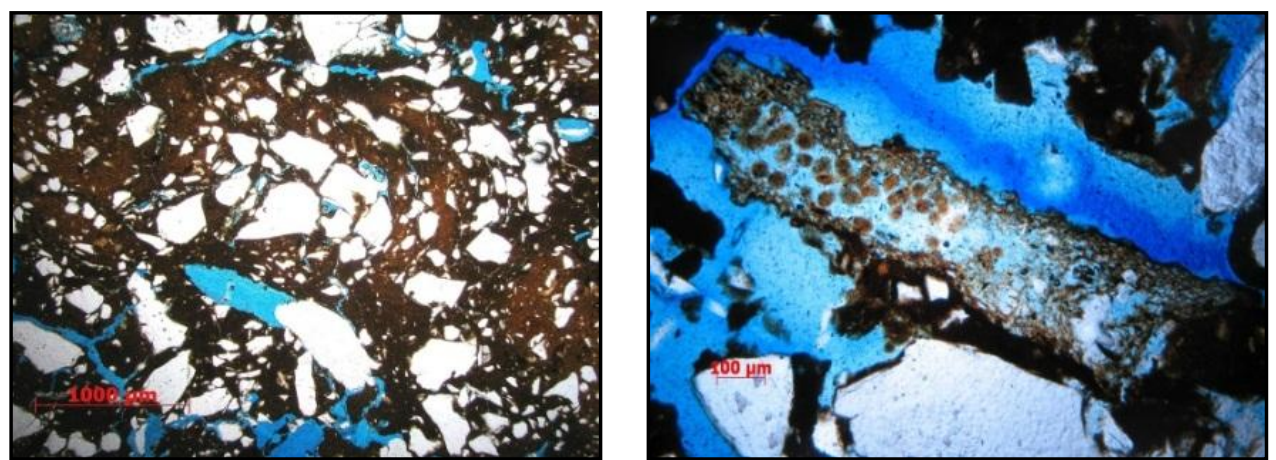

Figura 4: Fotomicrografias do solo do CM. LP: Luz plana. Aumento de 10x.

O sistema PC (Figura 5) apresentou, na profundidade de 11-22 $\mathrm{cm}$, poucas quantidades de pelotas fecais esféricas de coloração escura, já na profundidade de $25-36 \mathrm{~cm}$ não foi encontrada nenhuma ocorrência. Isto pode sugerir que a atividade biológica do sistema ocorre mais superficialmente, se diferenciando dos demais avaliados.

A ocorrência de atividades biológicas em todas as profundidades avaliadas no sistema $\mathrm{CM}$ e a falta de estruturas que demonstram atividades biológicas na parte subsuperficial do sistema PC é confirmada pelas análises de Carbono Orgânico Total (Figura 6), onde o sistema CM apresentou, no 
Regeneração de um solo sob agricultura orgânica em diferentes manejos: Estação Experimental da PESAGRO, Paty do Alferes - Rio de Janeiro. Rafaella Lima Paixão Fontes, Gisele Rodrigues Gomes, Ana Valéria Freire Allemão Bertolino e Luiz Carlos Bertolino geral, percentual muito maior do que o sistema PC, $5,1 \%$ e 2,8\%, respectivamente, e as análises por profundidade de C-Total corroboram esse comportamento, pois o sistema $\mathrm{CM}$ apresentou, em todas as análises, valores superiores ao sistema PC, tanto em superfície quanto em subsuperfície.
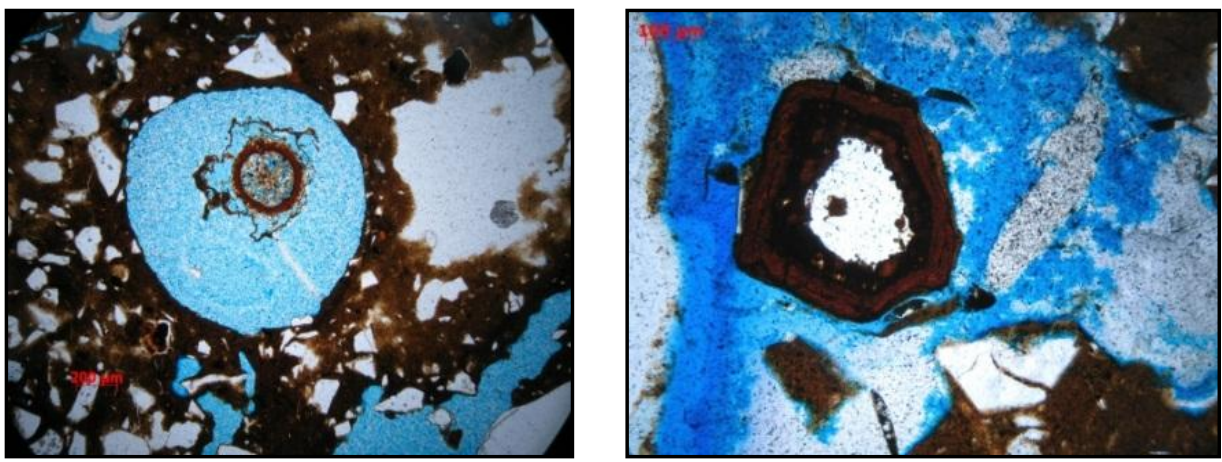

Figura 5: Fotomicrografias do solo do PC. LP: Luz plana.

A profundidade de $25-36 \mathrm{~cm}$, no sistema $\mathrm{PC}$, apresentou poros formados por canais, mas com presença de planares de rachadura e com maioria de ortoporos.

Os sistemas CM, PC e T0 apresentaram diferenciações em relação à tipologia e conexão da porosidade, em que o T0 e o sistema CM demonstraram maior semelhança e equilíbrio, possuindo maior quantidade de poros conectados e homogêneos ao longo do perfil, diferentemente do sistema PC que apresentou conexão reduzida e heterogênea.

Ao se avaliar quantitativamente o espaço poral dos sistemas estudados (Tabela 2), observouse que o sistema PC apresenta uma significativa diminuição da porosidade da profundidade $0-11 \mathrm{~cm}$ para a de $11-22 \mathrm{~cm}$, com valores respectivos de $33,7 \%$ e $18 \%$, caracterizando uma queda de $15,7 \%$ da porosidade. Demonstrando, assim, uma diminuição da porosidade da camada superficial para as partes inferiores do perfil.

O sistema CM apresenta uma homogeneidade dos poros ao longo do perfil, com percentuais muito semelhantes ao observado no T0. Já no sistema PC encontra-se o comportamento esperado, pois, em geral, áreas trabalhadas a partir da mecanização tendem a apresentar uma compactação em subsuperfície.

Tabela 2: Resultados da contagem do espaço poral obtidos pelo microscópio petrográfico nos sistemas PC, CM e T0

\begin{tabular}{|c|c|c|c|}
\hline Profundidade (cm) & $\begin{array}{c}\text { Área de Floresta } \\
\text { (To) }\end{array}$ & $\begin{array}{c}\text { Cultivo Mínimo } \\
(\mathbf{C M})\end{array}$ & $\begin{array}{c}\text { Plantio } \\
\text { Convencional (PC) }\end{array}$ \\
\hline $\mathbf{0 - 1 1}$ & $30,7 \%$ & $32,8 \%$ & $33,7 \%$ \\
\hline $\mathbf{1 1}-\mathbf{2 2}$ & $33,3 \%$ & $33,1 \%$ & $18 \%$ \\
\hline $\mathbf{2 5}-\mathbf{3 6}$ & $33,0 \%$ & $33,3 \%$ & $32 \%$ \\
\hline
\end{tabular}

\section{Carbono Orgânico Total (C-Total)}

Ao quantificar o percentual de C-total nos sistemas estudados (Figura 6), observou-se que o sistema CM apresentou significativamente um maior percentual de C-Total em detrimento ao sistema PC, sendo, respectivamente, $5,1 \%$ e $2,8 \%$. 

Rafaella Lima Paixão Fontes, Gisele Rodrigues Gomes, Ana Valéria Freire Allemão Bertolino e Luiz Carlos Bertolino

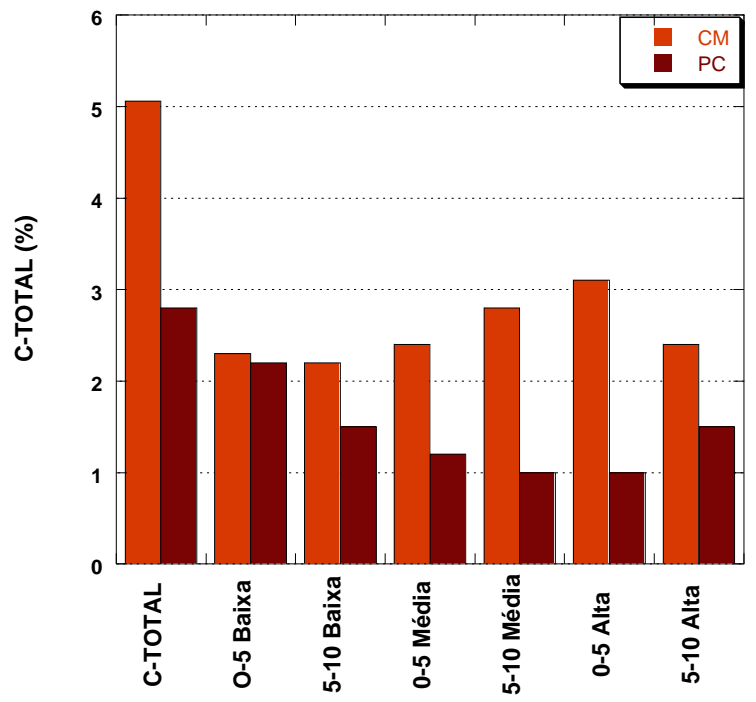

Figura 6: Carbono Orgânico Total (\%), das parcelas PC e CM, nas porções Alta, Média e Baixa da encosta.

Avaliando os valores de C-Total a partir das profundidades, observou-se que o sistema CM possui quantidade significativa de C-Total tanto em superfície quanto em subsuperfície, já o sistema PC demonstrou valores baixos em superfície e subsuperfície.

Na parte superficial $(0-5 \mathrm{~cm})$, observou-se que o percentual mais alto apresentado pelo sistema PC foi 2,2\% na vertente baixa da encosta, já o sistema CM apresentou o percentual máximo de 3,1\% na vertente alta.

É interessante observar que os valores superficiais de C-Total demonstraram que no sistema PC ocorre aumento dos percentuais de C-Total da parte alta da vertente $(1,0 \%)$ para a parte baixa (2,0\%), já o sistema CM apresenta o contrário, com a parte alta da vertente demonstrando maior percentual $(3,1 \%)$ em detrimento da parte baixa $(2,3 \%)$.

Tais valores podem ser explicados devido ao fato de o sistema PC apresentar um maior carreamento de sedimentos vertente abaixo a partir do escoamento superficial. Já o sistema CM, mantém a cobertura vegetal morta no solo, não sendo revolvido, diminuindo, assim, o escoamento superficial.

7A

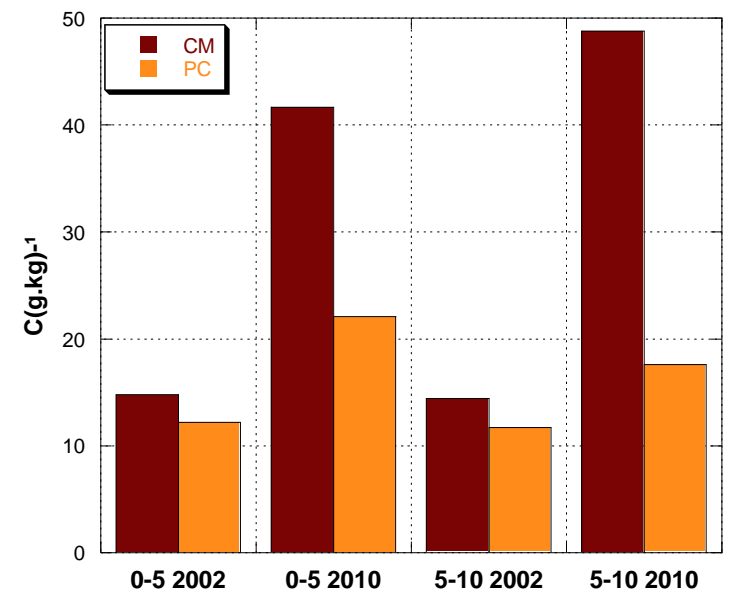

7B

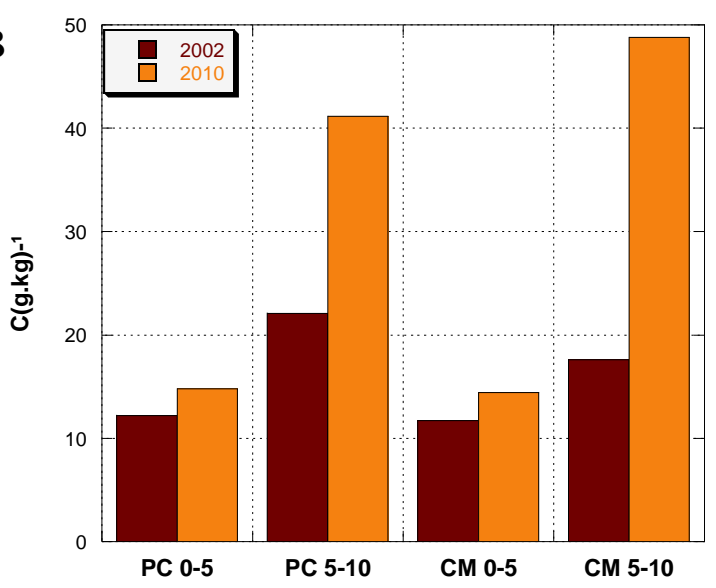

Figura 7A e 7B: Concentração de Carbono Orgânico e a avaliação de sua evolução temporal, em 2002 e 2010. 
Regeneração de um solo sob agricultura orgânica em diferentes manejos: Estação Experimental da PESAGRO, Paty do Alferes - Rio de Janeiro. Rafaella Lima Paixão Fontes, Gisele Rodrigues Gomes, Ana Valéria Freire Allemão Bertolino e Luiz Carlos Bertolino

Além dos dados percentuais de Carbono Orgânico, também foram avaliados os valores totais de Carbono Orgânico, considerando-se a quantidade em g/kg-1 no solo, em dois períodos (2002 e 2010), com o objetivo de observar as transformações temporais relacionadas a esse parâmetro (Figura 7A).

Constatou-se que tanto em 2002 quanto em 2010 (Figura 7A), o sistema CM apresentou valores de Carbono Orgânico, significativamente maiores do que o sistema PC, reafirmando que a forma de manejo conservacionista favorece a incorporação da cobertura vegetal no solo, favorecendo a agregabilidade e coesão das partículas do solo. O sistema PC também apresentou gradativo aumento nos valores de Carbono Orgânico, porém não foi tão expressivo quanto o observado no sistema CM.

Quanto à avaliação temporal (Figura 7B), os dados demonstraram que com o passar dos anos o sistema CM demonstrou aumento significativo nos valores de Carbono Orgânico, o que traduz a ideia de que, com a manutenção do tratamento conservacionista o solo vem apresentando melhorias quanto a um fator importante como a incorporação de nutrientes.

\section{Perda de solo por escoamento superficial}

Ao observar os totais gerais de perda de solo (Tabela 3) durante o período estudado (verão 2009/2010), observou-se que o sistema SC apresentou as maiores perdas de solo, com um total geral de 712,4 t/ha, seguido pelo sistema CM com uma perda de $0,06 \mathrm{t} / \mathrm{ha}$ e por fim o sistema PC com uma perda de $0,021 \mathrm{t} / \mathrm{ha}$.

Tabela 3: Total mensal, perda de solo (t/ha).

\begin{tabular}{|c|c|c|c|}
\hline Mês & CM & PC & SC \\
\hline Dezembro & 0,04 & 0,009 & 16,8 \\
\hline Janeiro & 0,01 & 0,007 & 14,6 \\
\hline Fevereiro & 0,01 & 0,005 & 671,3 \\
\hline Março & & & 9,7 \\
\hline Total & 0,06 & 0,021 & 712,4 \\
\hline
\end{tabular}

Comparando-se com o sistema SC, os sistemas PC e CM tiveram perdas de sedimentos pouco significativas o que reafirma a defesa da manutenção da cobertura vegetal no solo, independente da técnica adotada como medida preventiva à erosão.

\section{Perda de água por escoamento superficial}

O sistema SC apresentou valores totais muito mais significativos do que os sistemas PC e CM, com um total de $80,9 \mathrm{~mm}$, tal como nas análises de perda de solo. Ao observarmos somente os sistemas PC e CM, notou-se que o PC apresentou uma perda relativamente maior do que o CM, ainda que seja uma diferença muito pequena. Verificou-se que CM apresentou 4,7mm e o PC 4,8mm, sendo apenas $0,1 \mathrm{~mm}$ de diferença, conforme pode ser observado na Tabela 4. 
Tabela 4: Perda de água total mensal (mm).

\begin{tabular}{|c|c|c|c|c|}
\hline \multicolumn{7}{|c|}{ TOTAL MENSAL (mm) - Paty do Alferes } \\
\hline Mês & CM & PC & SC & Chuva (mm) \\
\hline Dezembro & 2,7 & 2,3 & 37,3 & 251,2 \\
\hline Janeiro & 1,4 & 2,0 & 29,4 & 159,8 \\
\hline Fevereiro & 0,6 & 0,5 & 9,5 & 119,8 \\
\hline Março & 0 & 0 & 4,7 & 156,6 \\
\hline Total & $\mathbf{4 , 7}$ & $\mathbf{4 , 8}$ & $\mathbf{8 0 , 9}$ & $\mathbf{6 8 7 , 4}$ \\
\hline
\end{tabular}

Ao analisar os valores de perda de água mensalmente, observou-se que os sistemas PC e $\mathrm{CM}$ apresentaram, a cada mês estudado, valores muito parecidos, e a maior variação ocorreu no mês de janeiro, com o PC demonstrando uma perda de 2,0 mm e CM 1,4 mm.

O fato do sistema CM apresentar perdas de água semelhante ao sistema PC é muito interessante, já que nas perdas de sedimentos o sistema $\mathrm{CM}$ apresenta uma perda maior do que o $\mathrm{PC}$, o que demonstra que o sistema $\mathrm{CM}$ absorve a quantidade de água necessária escoando o excesso, perdendo sedimentos sim, porém esse escoamento não prejudica tanto o solo quanto o escoamento no sistema PC que ao escoar água acaba por carrear, além de sedimentos, nutrientes importantes presentes em superfície. Fato que pode ser observado nas análises de C-Total onde o sistema PC apresenta os valores mais altos de Carbono Orgânico na vertente baixa da encosta, sugerindo um carreamento do mesmo, o que já não ocorre no $\mathrm{CM}$, que possui maiores índices de C-Total na vertente alta da encosta.

\section{CONCLUSÃO}

Observou-se que os sistemas CM e PC apresentaram modificações, oriundas da forma de manejo, em relação à estrutura do solo e porosidade, quando comparados ao $\mathrm{T} 0$, sendo que o CM apresenta uma uniformidade maior ao longo do perfil e uma maior atividade biológica o que favorece, entre outras coisas, uma melhor e mais homogênea percolação de água no perfil. O PC apresenta diminuição da porosidade, inclusive possuindo poros menos conectados, e uma mudança abrupta em relação à porosidade ao longo do perfil. A maior compactação deste sistema reflete no alto índice de desestruturação desse solo e maior suscetibilidade a erosão por escoamento superficial.

A atividade biológica foi verificada, especialmente na Área de Floresta, onde a vegetação é mais significativa e, consequentemente, há maior quantidade de material orgânico, oferecendo as condições ideais para a proliferação dos organismos. A presença de pelotas fecais, também, no sistema CM em todas as profundidades indica que o manejo conservacionista está atuando da maneira proposta, que é a de menor desestabilização da estrutura do solo.

Os valores de C-Total afirmam a eficácia da utilização de manejos conservacionistas em detrimento de manejos convencionais, onde o sistema $\mathrm{CM}$ obteve valores muito mais altos do que o sistema PC.

Com isso, é possível afirmar que o sistema CM vem sofrendo processo de regeneração do solo desde a superfície até a profundidade de $10 \mathrm{~cm}$ (máximo avaliado), enquanto o sistema PC vem perdendo sedimentos, Matéria Orgânica e água ao longo das profundidades avaliadas.

\section{REFERÊNCIAS BIBLIOGRÁFICAS}

BERTOLinO, A. V. F. A. Influência do Manejo na Hidrologia de Solos Agrícolas em 
Ambiente Serrano: Paty do Alferes - RJ. (Tese de Doutorado). Rio de Janeiro: Instituto de Geociências, UFRJ, 2004.

BERTONI, J. \& LOMBARDI NETO, F. Conservação do solo. Rio de Janeiro: Ed. Ícone, $4^{\circ}$ edição, 1999.

BREWER, R. Fabric and Mineral Analysis of Soils. Huntington, New York: Robert E. Krieger Publications Co., 2 Ed, 1976.

BREWER, R.; SLEEMAN, J.R. Soil structure and fabric: their definition and description. In: Journal of Soil Science. Oxford: $\mathrm{n}^{\circ}$ 11, 1960. p.172-185.

BULLOCK, P.; MURPHY, C.P. (Eds.). Soil Micromorphology. In: Proc. 6 Int. W. Meeting of Soil Micromorphology. Berkamsted: AB Academic Publs. v. I-Techniques and Applications, v. II- Soil Genesis, 1985. 705p.

CALDERANO, S. B \& LEMOS, A. L. Estudos Geológicos no Município de Paty do Alferes. In: WORKSHOP NACIONAL DE AGRICULTURA SUSTENTÁVEL EM REGIÕES TROPICAIS DE RELEVO ACIDENTADO, 3, 1997, Paty do Alferes: Anais... Rio de Janeiro: EMBRAPA-CNPS, 1998. CD-ROM.

CASTRO, S.S. Micromorfologia de solos: Bases para descrição de lâminas delgadas. Apostila. UFG/ IESA X UNICAMP/ IG/ DGEO. Apoio FUNAPE. Goiânia/ Campinas. 2002.

EMPRESA BRASILEIRA DE PESQUISA AGROPECUÁRIA. Manual de métodos de análise de solo. $2^{\text {a }}$ Ed. rev. e atual. Rio de Janeiro: EMBRAPA-CNPS, 1997, 212p. (EMBRAPA-CNPS. Série documentos n. ${ }^{\circ} 1$.)

ESWARAN, H. Point-count analysis as applied to soil micromorphology. Pedologie, Ghent, v. 18, n. 2, p. 238-252, 1968.

EMBRAPA - SOLOS. Projeto DESUSMO. Development of sustainable farming systems on mountainous, low fertility grazing land in South America. commission of the European communities, r\&d programme "life sciences and technologies for developing countries, Rio de Janeiro: EMBRAPA-CNPS,1998. 165p.

DRM-RJ - Sinopse Geológica do Estado do Rio de Janeiro. Mapa Geológico Escala 1:400.000 Niterói, RJ. 1995. 1v (60 p). p: 28-29 p

FERNANDES, B.; GALLOWAY, H. M.; BRONSON, R. D. et al. Efeito de três sistemas de prepare do solo na densidade aparente, na porosidade total e na distribuição dos poros, em dois solos (Typic Argiaquoll e Typic Hapludalf). Revista Brasileira de Ciência do Solo, Campinas, v. 7, n. 3, p. 329-333, set./dez. 1983.

FONTES, R. L. P. Análise Micromorfológica de solos sob influência de diferentes manejos em ambiente serrano: Paty do Alferes - RJ. Monografia UERJ/ São Gonçalo, 2010.

GOMES, G. R. Avaliação das perdas de água e sedimentos por escoamento superficial em parcelas de erosão sob diferentes manejos, em bioma de Mata Atlântica: Estação Experimental da PESAGRO - Paty do Alferes / RJ. Monografia (São Gonçalo), 2010.

HUDSON, N.W. Soil conservation. 3.ed. Ames, lowa State University Press, 1995. 391p.

KUNZMANN, M., PRINZ, D., PALMIERI, F. et al. Avaliação da perda de solo para diferentes manejos do solo no município de Paty do Alferes, RJ: um aspecto do projeto Desusmo. In: WORKSHOP NACIONAL DE AGRICULTURA SUSTENTÁVEL EM REGIÕES TROPICAIS DE RELEVO ACIDENTADO, 3, 1997, Paty do Alferes: Anais... Rio de Janeiro: EMBRAPA-CNPS, 1998. CD-ROM.

MACEDO, J.R., PALMIERI, F., PAULA, J.L. et al. Caracterização físico-hídrica dos solos da microbacia córrego da cachoeira, Paty do Alferes. In: WORKSHOP NACIONAL DE AGRICULTURA SUSTENTÁVEL EM REGIÕES TROPICAIS DE RELEVO ACIDENTADO, 3, 1997, Paty do Alferes. Anais... Rio de Janeiro: EMBRAPA-CNPS, 
1998. CD-ROM.

LUMBRERAS, J. F., CUNHA, T. J., MARTINS, J. S. et al. Levantamento semidetalhado de solos do município de Paty de Alferes e sub-bacias dos afluentes do córrego do saco-rio Ubá, estado do Rio de Janeiro. In: WORKSHOP NACIONAL DE AGRICULTURA SUSTENTÁVEL EM REGIÕES TROPICAIS DE RELEVO ACIDENTADO, 3, 1997, Paty do Alferes. Anais... Rio de Janeiro: EMBRAPA-CNPS, 1998. CD-ROM.

MARQUES, J.; PINHEIRO, F. M. A. Estudos hidrometeorológicos de Paty do Alferes, RJ: resultados preliminares. WORKSHOP NACIONAL DE AGRICULTURA SUSTENTÁVEL EM REGIÕES TROPICAIS DE RELEVO ACIDENTADO, 3, 1997 Paty do Alferes. Anais... Rio de Janeiro: EMBRAPA-CNPS, 1998. CD-ROM.

PINHEIRO, E. Frações orgânicas e agregação em Latossolo Vermelho em função de sistemas de oleráceas em Paty do Alferes, RJ. 2002. 77p. Dissertação - Mestrado em Agronomia (Ciência do Solo). Instituto de Agronomia. UFRRJ, Seropédica.

PORTELA, J. C.; COGO, N. P.; BAGATINI, T.; CHAGAS, J. P. \& PORTZ, G. Restauração da estrutura do solo por sequências culturais implantadas em semeadura direta, e sua relação com a erosão hídrica em distintas condições físicas de superfície. Revista Brasileira de Ciência do Solo, Nº34:1353-1364, 2010.

SILVA, T. M.; MOURA, J. R. S.; BAYERL, E.; ANDRADE, L. B.; PEIXOTO, M. N. O.; SALGADO, C. M.; LESSA, L. A \& SANTOS, D. A. Análise Geomorfológica do Município de Paty do Alferes. Workshop nacional de agricultura sustentável em regiões tropicais de relevo acidentado. In: WORKSHOP NACIONAL DE AGRICULTURA SUSTENTÁVEL EM REGIÕES TROPICAIS DE RELEVO ACIDENTADO, 3, 1997, Paty do Alferes. Anais... Rio de Janeiro: EMBRAPA-CNPS, 1998. CD-ROM.

TURETTA, A. P. D. Alterações edáficas em função do manejo agrícola de oleráceas em latossolo vermelho no bioma da Mata Atlântica, Paty do Alferes - RJ. 2000. 129p. Dissertação - Mestrado em Agronomia (Ciência do Solo). Instituto de Agronomia. UFRRJ, Seropédica.

WISCHMEIER, W. H. and SMITH, D. D. Rainfall energy and its relationship to soil loss. American Geophysical Union Transaction, Washington, v. 39, n.5, p. 285-291, 1958.

WU, L.; SWAN, J. B.; PAULSON, W. H. et al. Tillage effects on measured soil hydraulic properties. Soil and Tillage Research, Amsterdam, v. 25, n. 1, p. 17-33, oct. 1992. 